\title{
The Future of Aging as Reflected in José Saramago's Novel "Death with Interruptions" - Israel as a Case Study
}

\author{
Avi Bitzur ${ }^{1}$ \\ ${ }^{1}$ The head of the Applied Gerontology Section in the Health Managment Studies Faculty at MLA-the Center for \\ Accademic Studies at Or Yehuda, Israel \\ Correspondence: Avi Bitzur, The head of the Applied Gerontology Section in the Health Managment Studies Faculty at \\ MLA-the Center for Accademic Studies at Or Yehuda, Israel.
}

Received: September 18, 2017

Accepted: October 13,2017 Available online: October 18, 2017

doi:10.11114/ijsss.v5i11.2645

URL: https://doi.org/10.11114/ijsss.v5i11.2645

\begin{abstract}
Humanity has won one of the most challenging battles ever presented to it - the struggle to extend human life and increasing life expectancy. Current data and the figures predicted for future generations forecast significant longevity, and humanity has ostensibly marked a monumental achievement: containing death.

This achievement, however, is not without its challenges. This essay argues that humanity is not ready to deal with the challenges posed by aging and the dramatic increase in longevity. As the number of older people increases, so will social, political, human, economic, and health issues that are naturally associated with older age. Society will face a so-called "human tsunami," or, alternatively, a "demographic revolution" in which man will find himself preoccupied with his elders in a world that has not prepared for such a revolution.
\end{abstract}

This essay will review José Saramago's masterpiece "Death with Interruptions," which sarcastically describes a world free of death that, in turn, must contend with a myriad of problems. Faced with the issues plaguing Saramago's "deathless" world, authorities attempt to exercise a series of macabre and preposterous solutions vis-à-vis an issue that has all but upturned the "human pyramid" in the book.

The novel will serve as the backdrop for presenting the case study at the heart of this essay, aging in Israel. I will present the existing situation in terms of aging-oriented services in Israel and the issues, obstacles and shortcomings of the system currently in place.

This essay strives to illustrate the fact that global and Israeli society alike, fall short of rising to the challenges presented by this revolution, as the communities, families and the formal and informal state systems are not ready for the dramatic rise in longevity and its implications .

Only nations that prepare themselves from social, religious, healthcare, economic, and organizational standpoints ahead of time will be able to properly deal with this phenomenon.

Keywords: aging, life expectancy, community services, demographic revolution, healthcare, welfare

\section{Introduction}

"The following day, no one died. This fact, being absolutely contrary to life's rules, provoked enormous and, in the circumstances, perfectly justifiable anxiety in people's minds" (Saramago, 2005, p.7). This dramatic opening to author José Saramago's masterpiece "Death with Interruptions" seeks to inspire thoughts and insights in readers' minds with regard to the concept of death and its various aspects, including the direct link between one's old age and the end of his life - death.

Man has been dealing with this issue since the dawn of time: From Adam and Eve who, if not for the original sin, were allegedly never supposed to die, through Methuselah, Noah, Abraham and many others, to this day.

According to this extraordinary book, the intensive preoccupation with questions such as "will we die" and the "how" and "when" of it, has led man to deduct two prominent insights that serve as the basis for this essay: The first sees a world free of death as a joyous, remarkable possibility and an amazing achievement for humanity as a whole; and the second sees the significance of effectively "abolishing death" as a catastrophe, unless mankind properly prepares for 
this phenomenon.

These two insights serve as the basis for this paper, in which the perception and interpretation the author lends to the meaning of abolishing death are reviewed through the prism of the increase in human life expectancy.

This rise is sometimes referred to as the "tsunami of old age" (Shem Tov, 2012, p. 6) and it begs the question of whether all aspects of human society are ready for this revolutionary change. Can society cope with change in the familiar structure or the change in trade and economic practices, as well as with the cultural, philosophical, religious, and financial changes that will result from the increase in life expectancy? Is human society ready for a situation in which, "the rhomboid of the ages will be swiftly turned on its head, with a gigantic, ever-growing mass of old people at the top, swallowing up like a python the new generations?" (Saramago, 2005, p.15).

The case study presented in this paper is that of Israel, which is one of the leaders in the Western world in terms of life expectancy and also boasts a welfare system aimed at benefiting the elderly. Israel is facing the abovementioned social phenomenon as the dramatic increase in life expectancy is expected to double the number of the elderly in Israel from 930,000 in 2017 (Brodsky, Davis in: Rozin 2003, pp.289-362) to 1.8 million by 2035 (Brick, Yakovich, 2014, introduction).

The phenomenon of "demographic revolution" (Morken, 2012) and its implications are about to make their mark on the structure of Israeli society. On the one hand, the customary birthday blessing of "may you live until 120" corresponds with the first insight that rises from Saramago's book, but on the other hand, as suggested by his second insight, there are those who believe this blessing will turn into a curse. But is that true? Is it possible that some see the longevity of the elderly as a problem or a burden?

This sarcastic question is the basis of this essay, which focuses on the thinking and planning processes pertaining to the future of aging, given life expectancy projections in Israel. This discussion will feature quotations from Saramago's book rendered through the author's interpretation, which will challenge aging policies in Israel as the case study.

The choice of "Death with Interruptions" was not coincidental: Saramago takes his readers on a journey in a country free of the tyranny of death and this journey gives rise to numerous insights and interpretations of the difficulties along this path, which may seem like the road to happiness, but not in the reality illustrated by Saramago. If this is the case, what will happen in a country where the number of the elderly is expected to double within two decades? Is the state duly preparing to deal with all aspects of the future challenges? These will be some of the questions this paper seeks to deal with.

The essay will begin with a review of Saramago's book, which deals with the fictional "deathless" society"; it will then review the basic data with respect to the various relevant institutions and organizations in Israel dedicated to aging vis-à-vis the author's interpretation of the future of the elderly; and conclude by presenting possible alternatives for the future of the elderly in Israel. As Saramago himself wrote, "The following day, no one died. ... Humanity's greatest dream since the beginning of time, the happy enjoyment of eternal life here on earth, had become a gift within the grasp of everyone" (Saramago, 2005, p.7). Is it a utopia or a dystopia of old age in Israel? This paper strives to deal with this key question.

Dr. Avi Bitzur

Petach Tikav, Israel, 2017

\section{The Key Arguments in Saramago's "Death with Interruptions"}

"A nation that does not respect its past [its elders] has a barren present and its future is shrouded in uncertainty" (Allon, 1959, p.72)

"Death with Interruptions" revolves around three subplots focused on one female protagonist, as most of Saramago's books do, in this case, the Angel of Death. The theme running throughout the book is her decision to cease taking life in one nation only - Portugal.

The first plot focuses on what happens in a nation when, as it turns out, "the following day, no one died." The ensuing sense of elation includes a variety of nationalistic expressions, such as flying the nation's flag everywhere. Soon enough, however, euphoria gives way to the understanding that the fundamental order of things has changed and that, at least according to the author, the fact that no one dies poses a serious problem for the nation's residents.

Further illustrating how ill-prepared society is for the increase in life expectancy, Saramago goes on to illustrate how the ensuing issues become problems for the government to deal with, as well as for the undertakers association, insurance companies, pension funds, hospitals and retirement homes. Slowly but surely, the "rhomboid of the ages" is turned on its head and infinite old age - and with it every imaginable ailment - takes over the younger generations' life to become a serious burden. The extreme old age further disrupts religious life and philosophic perceptions, as well as the lives of 
all those who suddenly become the elderly's caregivers (Ballets and Ballets, 1990).

The first plot, accompanied by Saramago's sarcastic commentary and examples, then moves into the second, shorter plot, in which the Angel of Death realizes that the human beings in the country she has "blessed" simply cannot withstand the burden brought on by their "positive" adversity. She therefore decides to allot those destined to die "time to prepare," seeking to both restore natural order as well as give those destined to die time to put their affairs in order. Those destined to die are to "magically" receive a purple envelope and given seven days to prepare for their death. Saramago mocks the recipients' attempts to dodge the proverbial bullet, which includes unchecking the notification boxes for incoming email messages, as no one can cheat death.

The story then moves into the third plot, which sees the Angel of Death send her "purple letters" to those destined to die and to her amazement, one of the letters is marked "return to sender" several times. Taking on her earthly form, she visits the "death refusenik," who turns out to be a middle-aged cellist in a large orchestra, living with his dog, whose lifelong dream is to compose a great cello symphony. His innocence, honesty, demeanor, professionalism, love for his dog and his dream prompt her to withdraw the "purple letter" and lead her to support his dream of composing an unforgettable symphony and eventually, to fall in love with him. The book concludes with a love scene between the Angel of Death and the man destined to die, and as she refrains from giving him the letter, the next morning, as Saramago writes, "no one died."

The three plots are intertwined. For the purposes of this paper, the first plot is the prominent one, as in it Saramago illustrates the fact that he believes mankind is not ready for the coming demographic revolution. In his opinion, we are merely postponing the end by making cosmetic changes and failing to properly prepare, thus imposing social, physical, economic, religious, spiritual and cultural anguish on ourselves and our elderly, all while the proper preparation - if society is willing to make the change, of course -- could spare us the suffering.

The way in which Saramago presents the implications of the "rhomboid of the ages" turning on its head to his readers and his sarcastic solutions are presented below.

\section{Significances and Solutions to the "Suspension of Death" According to Saramago: The Implications for Old Age}

In his book, Saramago presents a number of meanings, some of which will be detailed here, to the fact that death is "on strike" in a particular country, and presents ridiculous solutions to the issues at hand, as is the nature of his satirical works. But this satire is significant and has various implications for human society as a whole and particularly for Israeli society, as I will demonstrate below. The premise of this paper is that in his fictional description of having "no death," Saramago touches on the rise in life expectancy and sarcastically highlights the absurdity by which man, who is ill-prepared for the unexpected, tries to deal with said longevity.

In the very first line of the book, the author illustrates his basic argument that mankind is not ready to deal with the wave of aging about to happen, saying, "The following day, no one died. This ... provoked enormous and ... perfectly justifiable anxiety in people's minds" (Saramago, 2005, p.7).

The author underscores his position further, again stressing humanity's lacking readiness to the "tsunami of old age," writing, "New Year's Eve had failed to leave behind it the usual calamitous trail of fatalities. There was, however, no shortage of blood. Bewildered, confused, distraught ... the firemen extracted from the mangled remains wretched human bodies that, according to the mathematical logic of the collisions, should have been well and truly dead, but ... remained alive." (Saramago, 2005, p.7)

He adds that even "the very ancient and venerable queen mother ... remained there in suspension, her frail body hovering on the very edge of life, threatening at any moment to tip over onto the other side, yet bound to this side by a tenuous thread" (Saramago, 2005, p.8).

This places the future of old age as a choice between two options: The first is that the "absence of death" will be welcomed and celebrated by the various elements of society - "humanity's greatest dream since the beginning of time, the happy enjoyment of eternal life here on earth, had become a gift within the grasp of everyone" (Saramago, 2005, p.8); meaning that the very idea is the fulfillment of the human purpose as well as one of the greatest challenges facing mankind.

"This would doubtless have provided a good, honest headline for the newspaper the following day," he writes, but the local editor-in-chief decided to go with the mundane "New Year, New Life" (Saramago, 2005, p.9); and that country's health minister tells reporters, "There is absolutely no reason for alarm. ... May I remind you that people were dying even yesterday and it would never have occurred to anyone to think that is alarming." (Saramago, 2005, p.9).

The second possibility he presents is that "although the word crisis is clearly not the most appropriate one to describe 
these extraordinary events." (Saramago, 2005, p.9), humanity's lack of readiness for a world where society is increasingly getting older could lead to the following catastrophe: "The rhomboid of the ages will be swiftly turned on its head,with a gigantic, ever-growing mass of old people at the top, swallowing up like a python the new generations, who, transformed for the most part into nursing or administrative staff to work at these eventide homes, after spending the better part of their lives caring for old crocks of all ages, both the normally old and the Methuselahs multitudes of parents, grandparents, great-grandparents, great-great-grandparents, great-great-great-grandparents, and so on, ad infinitum, (Saramago, 2005, p. 15).

The book, therefore, describes a world in which all laws have to change due to society's accelerated aging and the "absence of death." The structure of the family will change, the rules of trade and commerce will change, and human society will have to deal with accelerated aging that will affect the economy, politics, religion, philosophy, welfare issues, and every organization dealing with them (Shem Tov, 2012, pp. 6-9).

Saramago presents the chaos expected as a result of the "absence of death" in a way that clarifies to his readers that his intention is unequivocal: As the fictional state in the book is ill-prepared to deal with the reality of prolonged longevity, it is bound to plunge into chaos. The prime minister in this imaginary country explicitly says that his government was "determined to face with courage ... the complex social, economic, political and moral problems that the definitive extinction of death would inevitably provoke," thus informing the reader, in Saramago's words, that instead of assuming his nation has reached a state akin to nirvana, he was actually concerned about what the future may hold; and according to Saramago, he is indeed proven right (Saramago, 2005, pp. 17-20).

The consequences of the "absence of death" undermine the entire fabric of life of the society described in the book. Every area the author can think of is affected. The sarcastic descriptions of the problems are followed by the cynical descriptions of the solutions, which clearly illustrate his ridicule of the preparations pursued by society ahead of the dramatic rise in life expectancy, as he believes these solutions are too few, too late and fall too short of being relevant.

This is illustrated via several prominent examples: The first to be affected by this change are the morticians, who have lost their livelihood. Saramago makes it clear to his readers that as soon as society begins to endlessly age, there would be no one to bury and therefore all undertakers would become unemployed. The solution is to bury pets, with a full ceremony and at a full fee, so as to minimize the economic loss (Saramago, 2005, p. 25).

The second to be affected is, of course, the life insurance and pension industry. If no one dies, no one needs to have a life insurance policy on the one hand; while on the other hand, pension payments will skyrocket, as a growing number of elderly will collect them. Here, too, Saramago offers a surprising solution: The state approves a new law called "mandatory death at the age of $80, "$ by which anyone who reaches the age of 80 - and until then pays premiums to the insurance companies - will be officially declared dead, even if this does not occur biologically. The "alleged deceased" could then apply for new pension insurance, for the next 80 years and pending the next declaration of their "death." (Saramago, 2005, pp. 36-38).

The third to be affected are the hospitals. Saramago stresses that the issue is not healthcare because the healthcare system, in his opinion, has failed to deal with the alderfly's problems as they are preoccupied with logistical issues. In other words, the problem in a world "devoid" of death, with respect to hospitals, would be reflected in the fact that the cyclic process of patients entering the hospital, recovering or dying and so forth, will be impeded by the fact that no one will die. Live patients will continue to take up beds, thus exhausting hospitals' resources and bringing about their collapse. The solution Saramago offers is simple - make the families shoulder the burden instead of the state and its healthcare system. The elderly will "simply" be placed in the care of their families, where they will await the never-coming death (Saramago, 2005, p. 28).

The fourth to be affected are the nursing homes, where, according to Saramago, elderly masses will accumulate. The problem here is that "those charitable institutions created for the peace of mind of families who have neither the time nor the patience to ... tend to weary sphincters and get up at night to bring the bedpan, were not long in coming and beating their heads against the wailing wall, as the hospitals and undertakers had done before them," (Saramago, 2005, p. 33), thus undermining the families peace of mind.

In Saramago's own words, society "has been charged with the delicate task of reflecting on what a future without death will be like ... the principle of which some might summarize with this cruel question, what are we going to do with all the old people if death is not there to cut short any ambitions they may have to live an excessively long life" (Saramago, 2005, p. 33).

As nursing homes will exceed their capacity, new ones would have to be built at a huge expense. Here, too, Saramago mocks his readers by presenting the "obvious" solution - placing the elderly with their families - the same families who did everything within their power to place the elderly in nursing homes to begin with and now have to take them back. 
(Banister and Bowling, 2004).

The religious apparatus in the fictional country will also suffer, as it will be rendered obsolete. As the cardinal himself said, "If there was no death, there could be no resurrection, and if there was no resurrection, then there would be no point in having a church" (Saramago, 2005, p.18), meaning with the vision of resurrection rendered defunct, there is nothing more left to believe in. Saramago's magical solution here is, in true modern society form, to establish a committee tasked with devising solutions for the "future of a world without death." The committee will find that "death has not ended ... we know only that it has ceased to kill," meaning there is no need to worry, one needs to have faith that death will return and with it the natural order of things.

For the purpose of this paper, the last example will deal with Saramago's presentation of how the fictional nation's security apparatus, i.e. the police and military, collapse. He believes this is the result of the fact that the solution improvised by the country's residents opposite the reality of "with no death there are too many old people" is, in essence, illegal and akin to murder: the dying elderly are taken by the local mafia to a place beyond the border, where the Angel of Death still kills.

The security organizations turn a blind eye to this practice and chaos reigns in the fictional "deathless" nation. Saramago's paradoxical solution leads the state to enter into a contract with operatives of the underworld who smuggle the elderly across the border to die. Is it murder? Is it an immoral act? Do the smugglers benefit the population or violate the ultimate moral code?

This inspirational book shines a spotlight on the issue of accelerated aging everywhere in the world. The book places the debate at the forefront of the cosmopolitan public sphere and delves into questions relating to humanity as a whole, with the clear understanding that any solution will affect not only the elderly, but also the entire socio-cultural-economic structure in each country as it tries to resolve the issue.

Society as a whole will be affected by the realization of plans that deal with the implications of increased life expectancy. But, "the sooner the better" is the slogan that should guide both those who deal with this issue and those who try to ignore it, as the next chapter, which deals with basic implications in Israel's case, will demonstrate.

\section{Saramago's Ideas and Solutions - The Israeli Case}

This chapter will illustrate Israel as a case study for a nation that has begun outlining the necessary processes to deal with the accelerated aging of society but has yet to implement its policies or deal with the growing needs presented by the issues.

This essay will begin by presenting the current figures on aging in Israel; continue with briefly presenting the existing apparatus in Israel based on relevant data and offices tasked with handling the issue, illustrating the lacunae, omissions, errors, and failures that an ill-prepared system has created for the future; and conclude with a chapter that will offer a short outlook of what lies ahead, both the future of humanity and the future of Israel, based on Saramago's ideas.

Background: The Elderly in Israel, 2017 - Selected Dataㄹ.

In 2016, Israel's elderly population stood at 939,000, of these, 524,000 were women and 415,000 were men (Central Bureau of Statistics, September 2016). This represented a dramatic statistical increase: in 1948, at the time of Israel's inception, the elderly represented $4 \%$ of the population and numbered about 24,000 people. Today they make up $11.1 \%$ of the population and it is expected that by 2035 the elderly will account for $15 \%$ of the population, numbering 1.66 million (National Insurance Institute reports, 2014-2015).

At the same time, life expectancy, as a statistical average, is increasing. The average life expectancy for Israeli men is 81.5 and for Israeli woman - 84.5 years (The Elderly in Israel, Statistical Abstract 2015, p. 204). These numbers are interesting because, if we examine reliable sources from 2014, for example, we will find that life expectancy stood at 79.9 years for men and 83.6 years for women. Therefore, within two years there has been a significant change, indicating that Saramago's assumption for what the future holds is not unfounded.

Additional data which is at the basis for understanding old age in Israel are listed below as characteristics that illustrate elderly Israelis. These characteristics are not only the basis for the services provided to the elderly, but they are also at the heart of the gaps and failures resulting from the lack of proper planning for what the elderly may face in the future:

\footnotetext{
${ }^{1}$ These figures are selected data from reports by the National Insurance Institute of Israel and other aging research institutes in the country.
} 
- Nearly half of elderly Israelis (44\%) are age 75 and over. In other words, this number will rise in the future and will impede the economy's workforce.

- Some $50 \%$ of elderly Israelis live in the greater Tel Aviv area and $90 \%$ live in cities. Proper planning and zoning may promote a different dispersal of the population that avoids the urban concentration of the elderly.

- Only about $17 \%$ of elderly men work, meaning that the majority of the elderly depend on social security benefits and pensions, while most of them have no pension funds. (National Insurance Institutes reports 2014-2015). This spells a future burden on the social security system.

- Elderly Israelis struggle to pay their healthcare bills, purchase medication and ensure dental health, and some also suffer from a lack of nutritional security, meaning they are ill-prepared to deal with future health problems.

- The elderly's poverty threshold revolves around $25 \%$ out of 1 million. This is a significant number by all accounts, meaning that as the number of elderly rises, so will poverty rates.

- About 150,000 elderly Israelis suffer from a cognitive decline in their abilities and from some level of dementia (National Insurance Institute reports, 2014-2015), meaning a growing population presents increasing nursing needs which can never actually be met.

- Currently, welfare and nursing services afford between 10 and 18 hours of weekly assistance per person, while 160,000 elderly Israelis need nursing services at various levels (National Insurance Institute reports, 2014-2015). This means Saramago's prediction of the "rhomboid of the ages" turning on its head is correct.

- About $50 \%$ of elderly Israelis testify to subjective or even objective feelings of social isolation. In the future, this means that unless treated, the feeling of loneliness, anxiety and depression will consume the elderly.

- Recent years have seen an alarming increase in cases of elderly abuse, and some $20 \%$ now attest that they were neglected during their chronological old age. Some 27,000 criminal complaints over violence against elderly individuals are filed with the police each year and some $30 \%$ of elderly Israelis reported not feeling safe at home or in the community (Issakovich, Levenstein, Band-Winterstein, 2005). In other words, as the elderly population increases in numbers, so will the violence they experience.

- Only $19 \%$ of elderly Israelis use the internet and emails. As technology evolves in the future, the elderly will find it increasingly difficult to keep up with the changes.

Addressing the Needs of Elderly Israelis - Key Points

Israel's approach to meeting the needs of the elderly - presently, not in the future when life expectancy rises - is two-pronged, comprising an institutional, formal system alongside an informal one that is based on familial and independent voluntary resources.

These systems provide many varied answers to acute, real-time issues, but entail no future outlook (Litwin, 2009, pp. 71-91). Saramago's harsh vision, therefore, is taking shape in a society whose culture is rooted in the principles of "show respect for the elderly ${ }^{2}$ and "don't discard me in my old age ${ }^{3}$." Ne vertheless, it is precisely this society that lacks future planning and vision of how to deal with the needs derived from the rise in life expectancy and the significance of the reversal of the age pyramid.

This subsection will briefly illustrate the main issues with which the existing system of formal and institutional services deals in Israel. The next chapter will outline the main issues and flawed interpretations that Israeli decision-makers have made regarding these services. Decision-makers' errors with this respect have been significant and the toll they exact may spell the realization of Saramago's nightmare scenario (Chappelset, 2004).

The first issue plaguing Israeli policies is healthcare: Israel's formal elderly services system is based on the provisions of the National Health Insurance Law of 1995, which includes hospitals, healthcare clinics and professional medical practitioners and according to which elderly Israelis are eligible for complete medical care (Brodsky, Shneor, Beer, 2013). How is it then, that hospitals do not have enough beds to accommodate the elderly and, moreover, are shuttering their geriatric departments?

The second issue touches on nursing services, which $20 \%$ of elderly Israelis need. Howe ver, in order to receive these services the elderly must pass "dependency tests." Failure to meet the demands of these disgraceful tests denies them access to this aid. The number of elderly Israelis who "fail" is so high that the system effectively fails to meet this

\footnotetext{
${ }^{2}$ Leviticus 19:32

${ }^{3}$ Psalm 71:9
} 
sector's needs. The total demand for nursing needs by elderly Israelis comes to twice the assistance actually approved (Brick, Yakowitz, Katan, 2014, p. 42).

The third issue centers on housing for the elderly, who live in their own homes as part of "supportive community" frameworks ${ }^{4}$, in senior housing or in nursing homes. The lack of preparedness becomes very conspicuous at this point: Some $95 \%$ of elderly Israelis prefer to remain at home and in their community, meaning the system must gear toward dealing with about one million elderly people at their homes. But how?

The fourth issue is the social security and income support. This is based on National Insurance Institute old-age pension and income supplement, seeking to ensure the elderly remain above the poverty line, as well as various pension payments from other sources. The fact that some one million Israelis do not have a pension fund, together with the fact that old age pensions are currently pegged at NIS 2,400 (\$673), raises a future actuarial problem of the elderly's inability to properly support themselves on the one hand, and the national insurance mechanism's inability to withstand the "old-age tsunami" on the other hand.

The fifth issue focuses on the array of services available to elderly Israelis, which illustrates the future problem more acutely. The very definition of the elderly as requiring welfare services reflects their perception by society as feeble and unfit; and when considering that social services are unable to visit and supervise every elderly person - especially as about $70 \%$ do not need these services - one can easily predict what will happen in the foreseeable future, as life expectancy increases.

Additional services are provided in Israel in a decentralized ad hoc manner rather than under a central, national and integrative framework. These services are made available according to the locally available organizational and budgetary resources in the community, and the organizational or personal abilities of those providing them. Such services often include providing medical aid, cultural and recreational services in social clubs, operating senior citizen centers, sponsoring elderly-oriented getaways, funding heating in winter, and providing information and counseling services with volunteers from among the elderly (Brick, Yakowitz, Katan, 2014, pp. 52-45).

The most prominently evident issue is the lack of any central direction with respect to the provision of services. The multitude of services sans clear planning for the future only spells potential problem, just as Saramago describes in his book.

The understanding that the elderly population in the country across all sectors - Israelis, Arabs, women and dementia and Alzheimer's patients - is about to grow exponentially is clear, but no orderly plan has been put in place to meet this challenge. This is a "red light" alerting to the dangerous implications clearly lying ahead and of which Saramago writes.

\section{The Misinterpretation and Vague Future Ahead of Elderly Israelis}

The failure to engage issues pertaining to the future with respect to the increase in life expectancy has, in Israel's case, led to misinterpretations from which fundamentally incorrect perceptions have stemmed with regard to the necessary preparations required to meet the "tidal wave of old age" that society faces. This subsection will detail the wide range of issues that have been misinterpreted and the implications of these misconceptions, which spell future chaos.

- Appropriating old-age pensions universally, in a non-differential manner, will result in a deficit in national insurance funds.

- The absence of a national nursing insurance law will lead to an inability on the part of the state to provide the chronic, mentally and physically frail elderly with the necessary care at different levels.

- Conducting eligibility tests for assistance is degrading for the elderly and creates a situation in which not every elderly person receives the aid they need and deserve.

- Nursing rather than rehabilitation for elderly who have suffered cardiac failure or strokes will introduce a growing number of elderly people into the caregiving cycle while they could be rehabilitated as outpatients.

- The privatization of pension funds will lead to a situation in which, should a pension fund go under, the elderly would be left without a financial safety net to secure their future.

\footnotetext{
${ }^{4}$ Currently there are 261 supportive communities in Israel, each with about 200 households. In total, there are 38,831 households in which 51,336 elderly people live. They continue to live in their homes and are connected to emergency medical services via a distress button. A "community leader" handles their daily needs and organizes social activities. This framework is subsidized by the Welfare Services Ministry and the Joint Distribution Committee in Israel.
} 
- Lack of hospital beds in the periphery will lead to an increase in the elderly's mortality rate due to the lack of proper medical care.

- The shuttering of geriatric departments in hospitals will lead to failure to provide adequate and equal medical care to elderly patients, and to providing nonprofessional care that fails to meet the elderly's needs.

- Failure to implement a national program to eliminate violence, abuse and neglect of the elderly will lead to a sharp increase in the commission of crimes against the elderly in Israel.

- Institutional computerization schemes for efficiency purposes will erode equal access to information and services as the elderly will struggle to deal with automated electronic services, such as banking services.

- Failure to equate old-age pensions with minimum wage will lead to poverty and as a result to increased morbidity and the financial collapse of elderly Israelis.

- Failing to update the 25-year-old Israel's Senior Citizens Law will lead to a reality in which elderly Israelis depend on outdated legislation, which has effectively been stripped of its ability to serve the elderly sector.

- Failure to set a basket of culture, employment, entertainment and leisure services and activities for elderly Israelis will lead to unnecessary household expenses the elderly cannot afford, and to the inception of short-term, sporadic projects rather than long-term ones.

- The lack of inspectors to supervise core issues, such as supervising nursing homes, senior citizen clubs and various guardianships, will lead to the humiliation and degradation of elderly Israelis, and sidelining their issues on the public agenda.

- Failing to establish a national council on aging will lead to the decentralization of powers and an inability to properly meet the needs of the elderly.

- Failing to establish a national survey institute for the study of old age will lead to a loss of pivotal knowledge, as no one institute will centralize and synthesize the accumulated information about aging in Israel.

- The failure to raise retirement age for Israeli women will further deepen the gender gap and harm to elderly women in Israel.

- Failing to set up a mechanism to enforce the mandatory pension law will result in a situation in which approximately 2 million Israelis will be deprived of one of the main sources of income for elderly Israelis and will require income supplement.

- The lack a national master plan with respect to aging policy will lead to an inability to adequately address the needs of elderly Israelis in the future.

- The decentralization of powers rather than their integration will spell an inability to manage, organize and advance mechanisms geared toward coping with future needs and challenges.

- The lack of a national master plan to help the elderly cope with loneliness, anxiety and depression will intensify the negative consequences of these severe phenomena, and will lead to the psychological, cognitive and biological weakening of the elderly.

- Lacking investment in studies and drugs for Parkinson's disease, dementia and Alzheimer's disease will lead to an increase in the number of people suffering from these typical old-age diseases, thus increasing the number of individuals in need of nursing and hospitalization.

- Failing to increase nursing personnel standards in institutions or for elderly who are in need of care in the community will erode the number of caregivers and spell the eventual neglect of the elderly.

- The lack of a national master plan to deal with suicide rates among the elderly will lead to an increase in such incidents.

Saramago is not Israeli and the situation in Israel was, naturally, not on his mind while he was writing the book. Similarly, the case study outlined in this essay, of Israel and its elders, is a positive metaphor for the need to deal with the problems of old age now. But it is clear to the author of this paper that Saramago's sarcastic prophecy fits the situation in Israel with respect to policy makers like the proverbial glove.

The system does not view the situation as a crisis, exactly as Saramago describes it, and tries to manage and maneuver existing reality. The main problem is that those steering the ship have their work cut out for them: The increase in life expectancy may not bring about a "deathless" world as Saramago predicts, but it will generate a host of problems that must be addressed without delay, for future generations' sake.

This undertaking must be carried out with respect and appreciation for our elders' past, while crafting a solid and 
adequate situation for existing generations and building a safer future, one that can adequately meet future generations' needs.

\section{Conclusions}

To conclude, there is no doubt that human society in general, despite a number of programs ${ }^{5}$ (such as the WHO program, the Florida program, the Kyoto program and Ireland's national plan) that strive to deal with various aspects of old age, is ill-prepared to deal with the future challenges posed by the dramatic rise in life expectancy (Morken, 2012).

While the conclusions deducted as part of this paper are not unequivocal and are certainly debatable, it is clear that Israeli society is not properly prepared to meet the challenges posed by the upturning of the "age pyramid," nor is it prepared to deal with the fact that an increasing number of elderly people will become an inseparable part of it in the future. This lack of awareness is reflected from the ground-level and up, in the lack of clear agreement among those tasked with caring for elderly Israelis: the National Insurance Institute, the various associations and branches of government, such as the Health and Welfare ministries, national health funds, hospitals, etc. The absence of agreement centers around a fundamental question: Is old age a burden or an asset? This question has yet to be answered in Israel, (Kop, Bar-Tzuri, 2008, pp. 12-18), but it is pi votal in order to outline solutions for meeting the challenges posed by the future increase in life expectancy.

The correct assessment of all areas on which this paper touched, such as the implementation of integrative old-age policy and having one government ministry or directorate navigate the various derivative issues, thought certainly debatable, may solve the problem. A policy based on the perception that elderly Israelis are not a burden but rather an asset that encompasses knowledge and experience, as well as economic, physical, technological, professional and cultural abilities, can foster a situation in which old age becomes a blessing and contribution to Israeli society.

The observation and interpretation, and hence the implementation of aging policy in Israel are in line with Saramago's sarcasm. The Israeli perception is fraught with future problems and the subsequent implementation of its aging policy is based on awkward actuarial calculations that deal with future nursing expenses and making pension payments on the one hand while ignoring the contribution of Israel's founding generation to society on the other hand, which is a fatal error.

Saramago may not be Israeli but he held up a mirror for Israeli society and for humanity as a whole, showing us the impossible future toward which we are heading. So far, only local, sporadic and, for the most part, temporary attempts have been made to deal with the key issues instead of striving to fundamentally rectify the basis on which welfare, health, economic, insurance, employment and recreational services are offered to the elderly.

The main issues plaguing our elderly with respect to the future revolve around a number of key points, chief among them is the decentralization of the responsibility for services provided to the elderly. Other issues include the erosion of institutions such as the government treasury, the National Insurance Institute and pension funds; inadequate and unequal health services; inadequate nursing services and long-term care insurance, nursing hours and the absence of a national nursing law; the erosion of the elderly's social status, which leads to violence, abuse and neglect; the lack of investment in research of drugs for age-related diseases such as Alzheimer's, dementia and Parkinson's disease; and the need to combat three interrelated phenomena that are the Achilles' heel of healthy, quality aging - loneliness, anxiety and depression, which have become a major symbol of aging.

To these central points, which Saramago refers to in his book with blood-curdling cynicism, as well as to the ridiculous solutions he presents, one must add the distinctive characteristics unique to each society, its culture, geography and geopolitical balance. In Israel, for example, the issue of Holocaust survivors must certainly be added as a unique social characteristic.

While the author of this paper stresses that conclusions detailed here are not unequivocal and therefore debatable, Israeli society must set a number of ideological principles in order to deal with the future "old-age tsunami." The first is the understanding that old age is not a burden but an asset, as we may utilize the elderly's abilities to benefit not only their lives, but society as a whole.

The second is the realization that this issue must be entrusted to one centralized authority that will navigate the various legislative, organizational, political, economic, ideological and even educational and academic options. There is no need

\footnotetext{
${ }^{5}$ Various international plans striving to deal with the various issues stemming from the increase in life expectancy include, the World Health Organization' plan (elderly and healthy) - online; the Florida Program (People and the elderly) http://ldenaffairs.state.ffres/english/puls/ruls/Mastenplan/Fullopy; The Kyoto Program (Urban Master Plan) - online; The "Healthy Old Age" program (Ireland's national program of Ireland) - Positive Ageing-Starts Now! The National Positive Aging Strategy, Ireland, Department of Health, April, 2013 - online;
} 
for the decentralization that has been imposed on us and our elders, and there is no justification for the constant running around between government offices, public or private associations, and communal and national authorities.

There is no need for the department of elderly services in the Welfare Ministry if one exists at the National Insurance Institute. There is no need for a geriatric department in the Health Ministry and an adult education department in the Education Ministry, nor is there a need for an elderly sports and culture department in the Social Equality Ministry (formerly the Ministry of Senior Citizens Affairs).

The third ideological principle is the need for differentiation rather than uni versalism with respect to resource allocation for the elderly in Israel. The universal scheme by which everyone receives the same pension must be shelved.

The fourth ideological principle lies with a cultural-educational change that must be instilled in all of us with regard to turning seemingly outdated phrases such as "show respect for the elderly" to a way of life, and the sooner the better.

\section{References}

Allon, Y. (1959). A Curtain of Sand, Maarachot, Tel Aviv, p.72

Ballets, P. B., \& Ballets, M. M. (1990). "Psychological Perspectives on Successful Aging: The Model of Selective Optimization with Compensation," in: P.B., Ballets, (ed.), Successful aging. Perspectives from the Behavioral Sciences, 1-34, Cambridge, England. https://doi.org/10.1017/CBO9780511665684.003

Banister, D., \& Bowling A. (2004). "Quality of Life for the Elderly: The Transport Dimension". Transport Policy, 11, 105-115. https://doi.org/10.1016/S0967-070X(03)00052-0

Bar-Tzuri, R., \& Kop, Y. (2008). Guidelines to Aging Policy in Israel: Old Age - Between Burden and Asset, Taub Center for Social Policy Studies in Israel, Jerusalem.

Brick, Y., Yakowitz, E., \& Katan, Y. (2014). "Services for the Elderly in Israel: The Need for a National Master Plan," Gerontology and Geriatrics. Journal of Aging, the Israeli Society of Gerontology, 41 (2), 11-75.

Brodsky, J., \& Davis, M. (2003). "Demography and Epidemiology of Aging and the Elderly Population" in: Rosen, Arnold (ed.) (2003). Aging and Old Age in Israel, JDC, Jerusalem, 289-362.

Brodsky, J., Shneor, Y., \& Beer, S. (eds.)(2015). The Elderly in Israel, Statistical Abstract, 2015, the Myers-JDC-Brookdale Institute, Jerusalem, p.204.

Central Bureau of Statistics. (2013). Social Survey. Retrieved from: http://survys.cbs.gov.il/survey.html

Chappel, N., Havens, L., \& Hononany, B. et all (2004). "Comparative Costs of Home Cane and Residential Care". The Gerontologist, 44(3), 389-400. https://doi.org/10.1093/geront/44.3.389

Issakovich, Z., Levenstein, A., \& Band-Winterstein, T. (2005). A Survey of Abuse and Neglect of the Elderly in Israel, Haifa University, Haifa.

Litwin, H. (2009). "The Inter Relationship between Formal and Informal Care: A Study in France and Israel," in: Ageing and Society, 29(1), 71-91. https://doi.org/10.1017/S0144686X08007666

Morken, L. (2012). "New York and Atlanta: Cities plan for Aging population." Retrieved from: http://53.amazonaws.com.

National Insurance Institute of Israel - Quarterly Reports (2013). Retrieved from: http://www.btl.gov.il/publications/skiiza-shnatit/2013/documents/oni.pdf

National Insurance Institute of Israel - Quarterly Reports (2015). Retrieved from: http://www.btl.gov.il/publications/skiiza-shnatit/2015/documents/oni.pdf

Saramago, J. (2005). Death with Interruptions, Mariner Books, Wilmington, Massachusetts.

Shem, T. S. (ed.) (2012). "Life and Death, an Introduction". Odyssey, 15, 6-9, Hebrew University, Jerusalem.

\section{Copyrights}

Copyright for this article is retained by the author(s), with first publication rights granted to the journal.

This is an open-access article distributed under the terms and conditions of the Creative Commons Attribution license which permits unrestricted use, distribution, and reproduction in any medium, provided the original work is properly cited. 